\title{
Diversity of Growth Responses of Soil Saprobic Fungi to Recurring Heat Events
}

OPEN ACCESS

Edited by:

Fred Asiegbu,

University of Helsinki, Finland

Reviewed by:

Cledir Santos,

University of La Frontera, Chile Asha Janadaree Dissanayake, University of Electronic Science and Technology of China, China

*Correspondence: Matthias C. Rillig matthias.rillig@fu-berlin.de

Specialty section: This article was submitted to Fungi and Their Interactions,

a section of the journa

Frontiers in Microbiology

Received: 19 December 2019

Accepted: 25 May 2020

Published: 19 June 2020

Citation:

Szymczak A, Ryo M, Roy J and Rillig MC (2020) Diversity of Growth Responses of Soil Saprobic Fungi

to Recurring Heat Events.

Front. Microbiol. 11:1326.

doi: 10.3389/fmicb.2020.01326

\author{
Aleksandra Szymczak ${ }^{1,2}$, Masahiro Ryo ${ }^{1,2}$, Julien Roy ${ }^{1,2}$ and Matthias C. Rillig ${ }^{1,2 *}$ \\ ${ }^{1}$ Institute of Biology, Freie Universität Berlin, Berlin, Germany, ${ }^{2}$ Berlin-Brandenburg Institute of Advanced Biodiversity \\ Research, Berlin, Germany
}

As a consequence of ongoing climate change, the frequency of extreme heat events is expected to increase. Recurring heat pulses may disrupt functions supported by soil microorganisms, thus affecting the entire ecosystem. However, most perturbation experiments only test effects of single heat events, and therefore it remains largely unknown how soil microorganisms react to repeated pulse events. Here we present data from a lab experiment exposing 32 filamentous fungi, originally isolated from the same soil, to sequential heat perturbations. Soil saprobic fungi isolates were exposed to one or two heat pulses: mild $\left(35^{\circ} \mathrm{C} / 2 \mathrm{~h}\right)$, strong $\left(45^{\circ} \mathrm{C} / 1 \mathrm{~h}\right)$, or both in sequence $\left(35^{\circ} \mathrm{C} / 2 \mathrm{~h}+45^{\circ} \mathrm{C} / 1 \mathrm{~h}\right)$, and we assessed growth rate. Out of the 32 isolates 13 isolates showed an antagonistic response, 3 isolates a synergistic response and 16 isolates responded in an additive manner. Thus the 32 filamentous fungal isolates used here showed the full range of possible responses to an identical heat perturbation sequence. This diversity of responses could have consequences for soil-borne ecosystem services, highlighting the potential importance of fungal biodiversity in maintaining such services, particularly in the context of climate change.

Keywords: thermal stress, soil saprobic fungi, global change, climate extreme, multiple perturbation events, stress priming

\section{INTRODUCTION}

Climate warming is threatening ecosystems worldwide (IPCC, 2018). Climate change does not only mean increased temperature averages but also increased frequency of extreme events, such as summer heatwaves (Hanson et al., 2006; Bárcenas-Moreno et al., 2009; Frank et al., 2015; IPCC, 2018). Such extremes can profoundly influence individual physiological performance and fitness, phenotypic plasticity, demography and population dynamics, species interactions, and community structure (Vázquez et al., 2015 and references therein), probably even more so than an increase in mean conditions (Thompson et al., 2013).

Performances of soil microbes under an elevated average temperature have been widely investigated (Hortal et al., 2016), but the responses to heat pulse perturbations are understudied (Jentsch et al., 2007; Kreyling and Beier, 2013). Temperature pulse perturbations occurring within a short period of time can be especially damaging, because soil organisms may not be able to adjust their physiological response fast enough (Alley et al., 2003; Fischer and Knutti, 2015). Nevertheless, most temperature-related experimental designs have minimized temperature variability to solely 
TABLE 1 | Interaction types describing the outcome of multiple stressors (perturbations) following Crain et al. (2008) and Côté et al. (2016).

\begin{tabular}{|c|c|c|c|}
\hline & \multicolumn{3}{|c|}{ Individual treatment response } \\
\hline & \multirow[t]{2}{*}{ Additive } & \multicolumn{2}{|c|}{ Non-additive } \\
\hline & & Synergy & Antagony \\
\hline Condition & $\begin{array}{l}\text { No significant } \\
\text { interaction term } \\
\text { between milder } \\
\text { perturbation (M) } \\
\text { and stronger } \\
\text { perturbation (S) }\end{array}$ & $\begin{array}{l}\text { A significant } \\
\text { interaction term } \\
\text { between milder } \\
\text { perturbation (M) } \\
\text { and stronger } \\
\text { perturbation (S) }\end{array}$ & $\begin{array}{l}\text { A significant } \\
\text { interaction term } \\
\text { between milder } \\
\text { perturbation (M) } \\
\text { and stronger } \\
\text { perturbation (S) }\end{array}$ \\
\hline Outcome category & $\begin{array}{l}\text { The effect of MS } \\
\text { is the equivalent } \\
\text { of the addition of } \\
\text { the single effects } \\
\text { of } M \text { and S }\end{array}$ & $\begin{array}{l}\text { The effect of MS } \\
\text { is stronger than } \\
\text { the added effects } \\
\text { of M and S }\end{array}$ & $\begin{array}{l}\text { The effect of MS } \\
\text { is weaker than } \\
\text { the added effects } \\
\text { of M and S }\end{array}$ \\
\hline
\end{tabular}

M, milder perturbation; S, stronger perturbation; MS, both perturbations applied.

focus on the effects of one average temperature (Lloret et al., 2012; Thompson et al., 2013). Understanding how heat pulse perturbations affect soil microbial performance is an important issue in soil ecology that could lead to a better understanding of aboveground and belowground community functioning.

In particular, the responses to multiple perturbations are far less understood but important, since multiple events may result in diverse response types because the effect size of a single event may depend on the antecedent event, known as ecological memory or carryover effect (Ryo et al., 2019). Considering the growing threat of recurrent heatwaves, it has been recently advocated that experiments aimed at investigating the impact of extreme weather events should consider that today's extremes will become the normal fluctuations in the future; and experimental designs should exceed the level of severity that we currently observe to provide an insight into an organism's responses to conditions harsher than those under which they evolved (Bahn et al., 2014; Kayler et al., 2015; Foster et al., 2016). Nevertheless, how soil saprobic fungi respond to recurrent temperature pulse perturbations is largely unknown. This is a large gap, since soil filamentous fungi are sensitive to global change (Rillig et al., 2019) and are important players in many soil processes, including decomposition, respiration and soil aggregation.

The combination of multiple stressors (perturbations) can result in additive effects, detrimental effects (i.e., synergism) or cause a reduction in effects (i.e., antagonism) (Mittler, 2006).

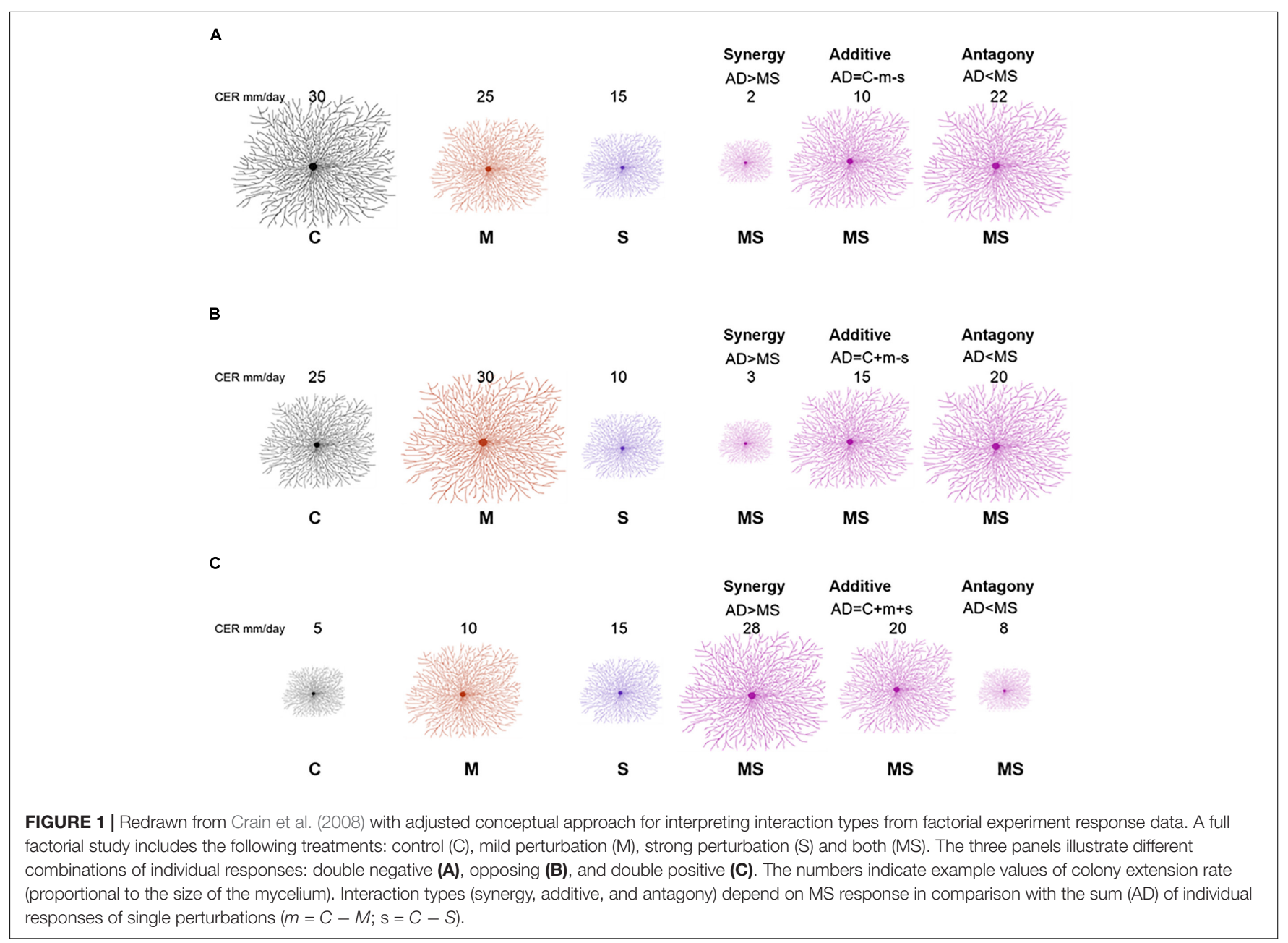



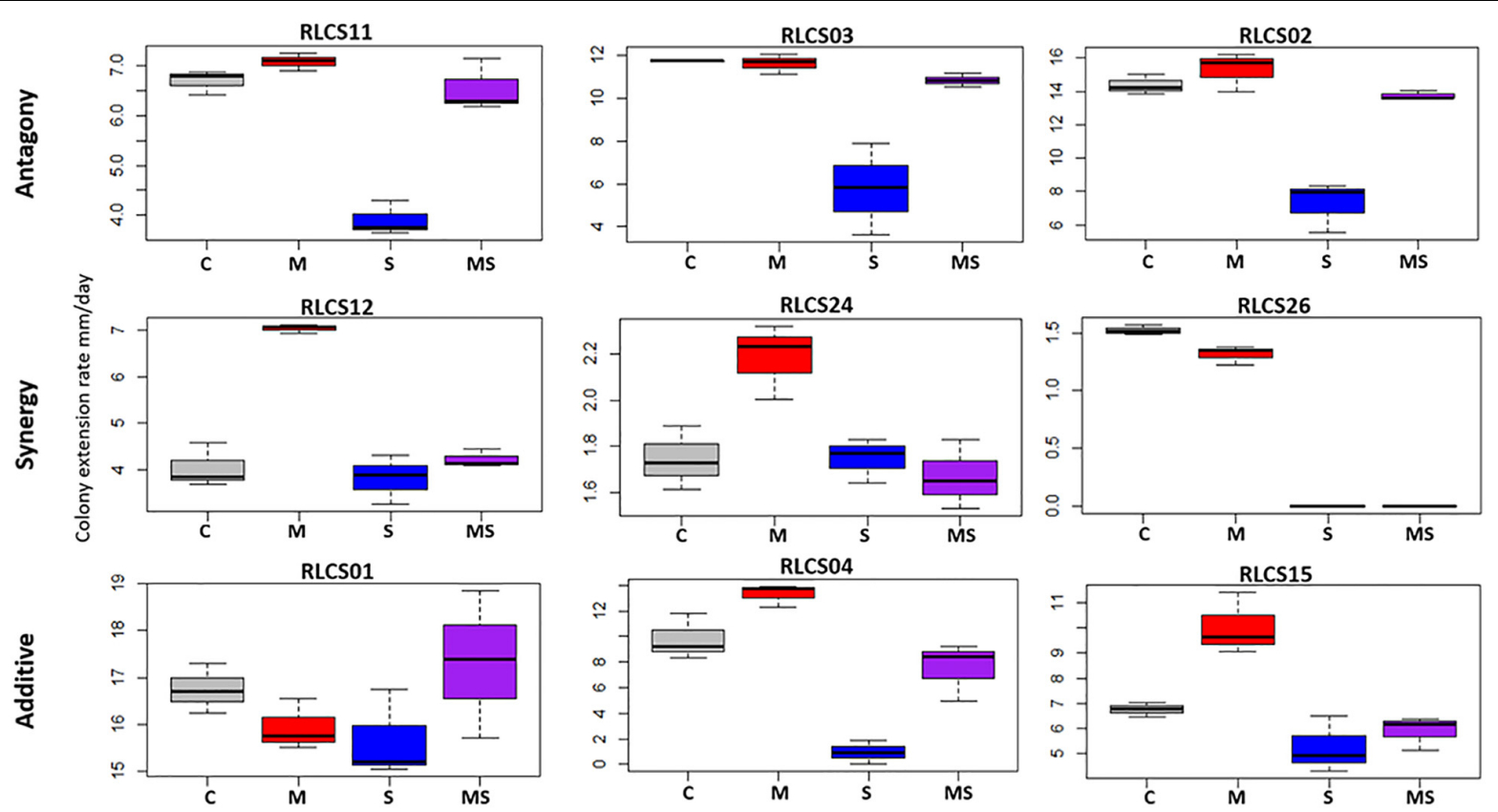

FIGURE 2 | Examples of response categories (based on colony extension rate) to applied recurrent heat pulse perturbations: antagony (shown are 3 of the 13 isolates so categorized), synergy (all 3 isolates in this category are shown), additive ( 3 of the 16 isolates so categorized are depicted). For a full figure containing data for all 32 isolates see Supplementary Figure S1.

Additive effects means that stressors do not interact and therefore the combined effect is simply the sum of each effect. Synergy results from a positive interaction, exceeding the sum of negative effects caused by each single stress event (Côté et al., 2016). Antagonism means that the combined effect is lower than the sum of each (negative) effect, such as observed in the form of stress priming ability (Rillig et al., 2015; Hilker et al., 2016). Priming ability means that a first exposure to a milder stress event induces protection mechanisms, consequently alleviating the effect of a subsequent stronger stress event (Rillig et al., 2015; Andrade-Linares et al., 2016; Hilker et al., 2016). While such different response types are theoretically possible, there is no study testing if such diverse responses to recurrent heat pulses are present in soil microbes co-occurring in the same environment. Additionally, studies on pulse temperature perturbations focus mostly on the community perspective, not providing information on species-level physiological responses (Norris et al., 2002; Allison and Martiny, 2008; Crowther and Bradford, 2013; Bérard et al., 2015; Zhou et al., 2017).

The purpose of the present study was to investigate the diversity of growth responses of soil filamentous fungi to sequential high-temperature pulses exceeding current adverse extreme conditions. We investigated how recurrent temperature pulses affect the performance of individual fungi from a set of 32 soil filamentous fungi that had been isolated from the same soil. We exposed fungi to one or two high-temperature pulse perturbations differing in magnitude $\left[35^{\circ} \mathrm{C} / 2 \mathrm{~h}\right.$ - mild (M), $45^{\circ} \mathrm{C} / 1 \mathrm{~h}$ - severe (S), and the sequence of these two perturbations $35^{\circ} / 2 \mathrm{~h}+45^{\circ} \mathrm{C} / 1 \mathrm{~h}$ (MS)] and measured growth responses (colony extension rates). We expected the following: (1) exposure of soil saprobic fungi to recurrent temperature pulses will lead to diverse, isolate-specific responses and (2) the diversity of responses to recurrent pulse temperature disturbance is phylogenetically conserved.

\section{MATERIALS AND METHODS}

\section{Fungal Isolates}

Isolates of 32 soil fungi were originally cultured from the top $10 \mathrm{~cm}$ of soil in a semi-arid grassland in Mallnow Lebus, Brandenburg, Germany (Andrade-Linares et al., 2016). Fungi are referred to by their strain number here; for more detail on these strains see Lehmann et al. (2019) and Supplementary Table S1. We chose this number of isolates to cover major groups (Basidiomycota, Ascomycota, and Mucoromycota), while still having a manageable set of fungi with which to conduct experiments. To obtain material for the experiment, $6.5 \mathrm{~mm}$ plugs were taken from the edge of fungal colonies and placed centrally on $9 \mathrm{~cm}$-diameter Petri dishes with potato dextrose agar (PDA) medium. Plates were then incubated at $22^{\circ} \mathrm{C}$ for $1-$ 5 days, depending on individual colony extension rates, to obtain fresh and actively growing material for inoculation. Then, fungi were re-inoculated on fresh PDA plates and placed in incubators for the experiment.

\section{Heat Treatment}

In the field where the fungi were collected, the topsoil (at approx. $10 \mathrm{~cm}$ depth) temperature recorded in the year $2018\left(52^{\circ} 52.778^{\prime} \mathrm{N}, 14^{\circ} 29.349^{\prime} \mathrm{E}\right)$ (Andrade-Linares et al., 2016) 


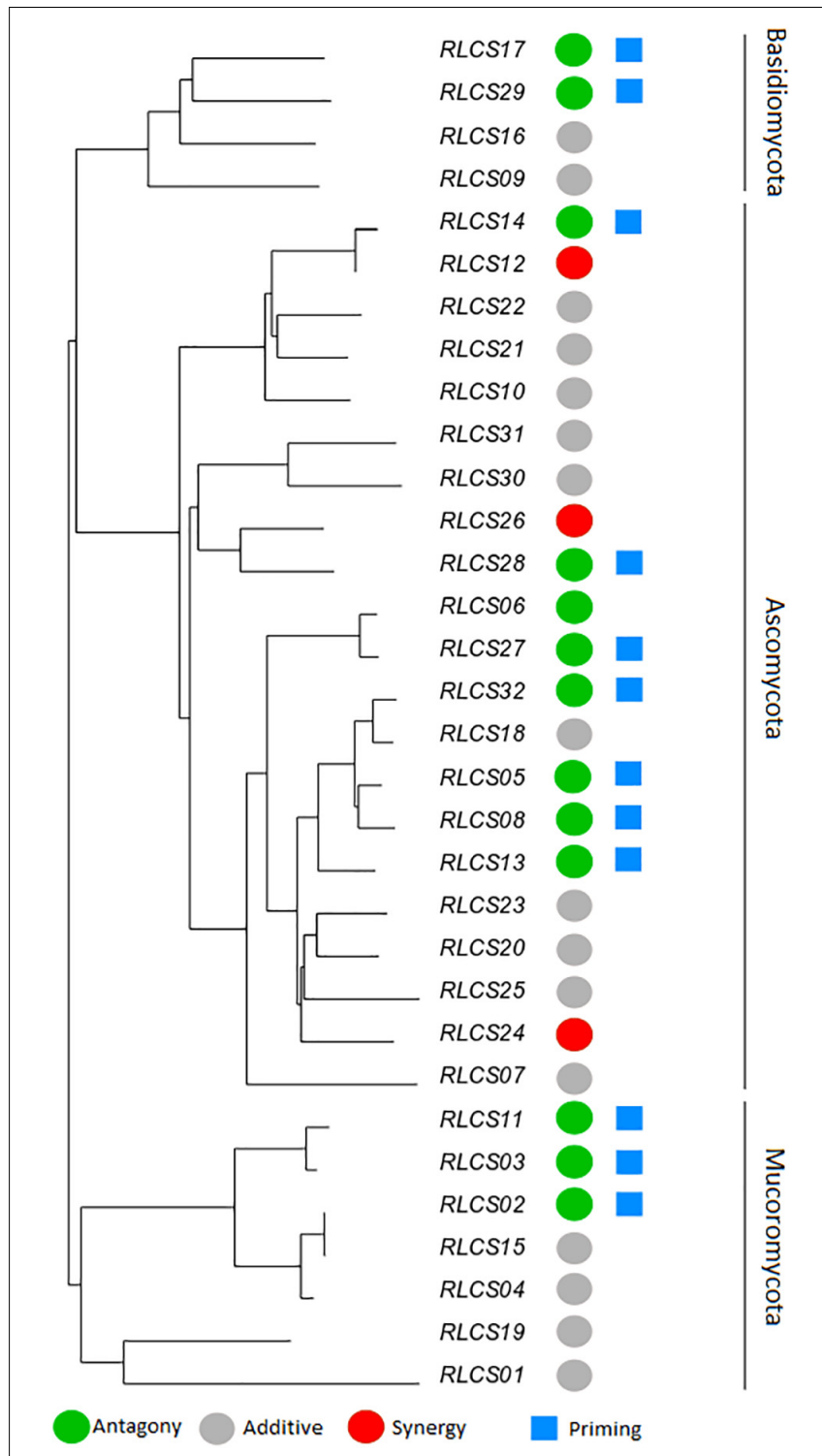

FIGURE 3 | Phylogenetic relationship of a set of soil fungal isolates originating from the same field site with the representation of diverse responses of fungal colony extension rate to recurrent heat pulse perturbations $(2 \mathrm{~h}$ mild perturbation $35^{\circ} \mathrm{C}+1 \mathrm{~h}$ strong perturbation $45^{\circ} \mathrm{C}$ ). The colored circles represent response types: antagony (green) (13 isolates); synergy (red) (3 isolates); additive (gray) (16 isolates). Blue squares mark isolates (12) that showed priming ability [based on criteria of Andrade-Linares et al. (2016)]. The remaining isolates (19) did not meet the criteria of priming ability. The neighbor-joining tree was based on ITS and LSU regions; detailed information on isolates is in Supplementary Table S1.

reached $32^{\circ} \mathrm{C}$ (Andrade-Linares et al., 2016; Dr. Max-Bernhard Ballhausen, personal information, data not shown). We used $35^{\circ} \mathrm{C} / 2 \mathrm{~h}$ as the mild perturbation (M) pulse temperature, since it is a temperature outside of the range of optimal growth conditions for half of the tested isolates, and it resulted in growth reduction in half of the tested fungi (Andrade-Linares et al., 2016). As the severe perturbation (S), we used $45^{\circ} \mathrm{C}$ applied for $1 \mathrm{~h}$ since the responses to this temperature were severe for most of the isolates in our set (Andrade-Linares et al., 2016).

The full factorial experiment consisted of the following treatments: control (C) $22^{\circ} \mathrm{C}$; mild perturbation $(\mathrm{M})\left(35^{\circ} \mathrm{C} / 2 \mathrm{~h}\right)$; severe perturbation (S) $\left(45^{\circ} \mathrm{C} / 1 \mathrm{~h}\right)$; and sequence of the two perturbations (MS) $\left(35^{\circ} \mathrm{C} / 2 \mathrm{~h}+45^{\circ} \mathrm{C} / 1 \mathrm{~h}\right)$.

Temperature pulses were applied uniformly to all 32 soil saprobic fungi. Each treatment consists of three replicates, with incubators used as experimental units. First, samples were incubated for 2-6 days to allow a fungal colony to begin growing from the inoculated plug. Then fungi were exposed to the different pulse temperature perturbations.

\section{Trait Measurements}

The colony diameter of each isolate was measured for each Petri dish in two directions, at right angles to each other. Such measurements were taken four times - the first time before starting heat treatments to determine initial colony size, and then three more times after the treatment to define the response to heat exposure. The frequency of diameter measurements was isolate dependent and taken daily for fast-growing fungi or every 2-4 days for slow-growing individuals.

Thus, in total 1,536 data points were acquired [i.e., 32 isolates $\times(2$ temperatures magnitudes $(\mathrm{M}, \mathrm{S})+1$ temperature combination (MS) + control (C) $) \times 3$ replicates $\times 4$ time points]. The diameter was measured repeatedly to calculate colony extension rate $\left(\mathrm{mm} \mathrm{day}^{-1}\right)$.

\section{Statistical Analyses}

Colony extension rates after heat treatments were used as a response variable to applied temperature pulses. Treatment effects were tested with two-way ANOVA where factors were the applied temperature regimes: mild perturbation ( $\mathrm{M}$, yes/no) and stronger perturbation ( $\mathrm{S}$, yes/no). Note that the no-no combination indicates control, while the yes-yes combination indicates two perturbations. The significance level $\alpha$ was set to 0.05 with Benjamini-Hochberg correction, to control for experiment-wise type I error rate.

We used this analysis to classify responses of fungi. Specifically, response classification is based on additive null model expectations, used to identify interactions (antagony, synergy, and additivity) between multiple perturbations (Crain et al., 2008; Côté et al., 2016). The additive null model has been reported to fit responses such as growth (colony extension) of an organism and is consistent with the use of ANOVA for factorial experimental data (Piggott et al., 2015; Côté et al., 2016). Response types were assigned to three groups (see Table 1). The effect direction of the two single perturbation effects in this study could be double negative (both single perturbations reduce the growth rate of the fungal isolate), opposing (one single perturbation increases the growth rate and the other single perturbation decreases the growth rate of the fungal isolate) or double positive (both single perturbations increase the growth rate of the fungal isolate) (Figure 1). Those effect directions are crucial to assign a response to interaction types (Crain et al., 2008). 
TABLE 2 | Analysis of variance results of effects of mild (M, yes $/ \mathrm{no})$ ), strong (S, yes/no), and both heat stress events (MS).

\begin{tabular}{|c|c|c|c|c|c|}
\hline Isolate & Source & df & Sum Sq & $F$ & $\begin{array}{c}p \text {-value } \\
\text { (Benjamini-Hochberg } \\
\text { corrected) }\end{array}$ \\
\hline \multirow[t]{4}{*}{ RLCS09 } & Mild & 1 & 0.00 & 0.00 & 0.98 \\
\hline & Strong & 1 & 0.00 & 0.01 & 0.97 \\
\hline & Mild:Strong & 1 & 0.01 & 0.05 & 0.85 \\
\hline & Residuals & 8 & 1.32 & & \\
\hline \multirow[t]{4}{*}{ RLCS16 } & Mild & 1 & 0.20 & 0.64 & 0.57 \\
\hline & Strong & 1 & 0.60 & 1.89 & 0.24 \\
\hline & Mild:Strong & 1 & 0.02 & 0.06 & 0.85 \\
\hline & Residuals & 8 & 2.54 & & \\
\hline \multirow[t]{4}{*}{ RLCS17 } & Mild & 1 & 0.19 & 1.94 & 0.38 \\
\hline & Strong & 1 & 1.84 & 19.16 & 0.01 \\
\hline & Mild:Strong & 1 & 1.45 & 15.09 & 0.01 \\
\hline & Residuals & 8 & 0.77 & & \\
\hline \multirow[t]{4}{*}{ RLCS29 } & Mild & 1 & 0.00 & 0.01 & 0.96 \\
\hline & Strong & 1 & 1.25 & 61.86 & 0.00 \\
\hline & Mild:Strong & 1 & 0.51 & 25.24 & 0.00 \\
\hline & Residuals & 8 & 0.16 & & \\
\hline \multirow[t]{4}{*}{ RLCS10 } & Mild & 1 & 1.36 & 10.76 & 0.03 \\
\hline & Strong & 1 & 1.16 & 9.22 & 0.02 \\
\hline & Mild:Strong & 1 & 0.82 & 6.49 & 0.06 \\
\hline & Residuals & 8 & 1.01 & & \\
\hline \multirow[t]{4}{*}{ RLCS14 } & Mild & 1 & 1.40 & 26.14 & 0.00 \\
\hline & Strong & 1 & 0.15 & 2.72 & 0.18 \\
\hline & Mild:Strong & 1 & 0.79 & 14.74 & 0.01 \\
\hline & Residuals & 8 & 0.43 & & \\
\hline \multirow[t]{4}{*}{ RLCS12 } & Mild & 1 & 8.66 & 63.93 & 0.00 \\
\hline & Strong & 1 & 6.84 & 50.45 & 0.00 \\
\hline & Mild:Strong & 1 & 5.02 & 37.04 & 0.00 \\
\hline & Residuals & 8 & 1.08 & & \\
\hline \multirow[t]{4}{*}{ RLCS22 } & Mild & 1 & 0.01 & 0.23 & 0.73 \\
\hline & Strong & 1 & 0.23 & 6.91 & 0.04 \\
\hline & Mild:Strong & 1 & 0.07 & 2.05 & 0.24 \\
\hline & Residuals & 8 & 0.27 & & \\
\hline \multirow[t]{4}{*}{ RLCS21 } & Mild & 1 & 0.26 & 1.64 & 0.40 \\
\hline & Strong & 1 & 7.05 & 44.20 & 0.00 \\
\hline & Mild:Strong & 1 & 0.47 & 2.93 & 0.18 \\
\hline & Residuals & 8 & 1.28 & & \\
\hline \multirow[t]{4}{*}{ RLCS31 } & Mild & 1 & 0.00 & 0.40 & 0.65 \\
\hline & Strong & 1 & 0.84 & 119.36 & 0.00 \\
\hline & Mild:Strong & 1 & 0.03 & 3.95 & 0.12 \\
\hline & Residuals & 8 & 0.06 & & \\
\hline \multirow[t]{4}{*}{ RLCS30 } & Mild & 1 & 0.02 & 1.42 & 0.43 \\
\hline & Strong & 1 & 1.72 & 102.66 & 0.00 \\
\hline & Mild:Strong & 1 & 0.01 & 0.59 & 0.55 \\
\hline & Residuals & 8 & 0.13 & & \\
\hline \multirow[t]{4}{*}{ RLCS26 } & Mild & 1 & 0.03 & 15.26 & 0.01 \\
\hline & Strong & 1 & 6.04 & 2933.90 & 0.00 \\
\hline & Mild:Strong & 1 & 0.03 & 15.26 & 0.01 \\
\hline & Residuals & 8 & 0.02 & & \\
\hline \multirow[t]{2}{*}{ RLCS28 } & Mild & 1 & 0.01 & 1.04 & 0.51 \\
\hline & Strong & 1 & 0.82 & 123.11 & 0.00 \\
\hline
\end{tabular}

(Continued)
TABLE 2 | Continued

\begin{tabular}{|c|c|c|c|c|c|}
\hline Isolate & Source & df & Sum Sq & $F$ & $\begin{array}{c}p \text {-value } \\
\text { (Benjamini-Hochberg } \\
\text { corrected) }\end{array}$ \\
\hline & Mild:Strong & 1 & 0.47 & 69.89 & 0.00 \\
\hline & Residuals & 8 & 0.05 & & \\
\hline \multirow[t]{4}{*}{ RLCSO7 } & Mild & 1 & 3.20 & 10.42 & 0.03 \\
\hline & Strong & 1 & 5.36 & 17.43 & 0.01 \\
\hline & Mild:Strong & 1 & 0.04 & 0.12 & 0.84 \\
\hline & Residuals & 8 & 2.46 & & \\
\hline \multirow[t]{4}{*}{ RLCS06 } & Mild & 1 & 2.02 & 7.87 & 0.05 \\
\hline & Strong & 1 & 4.91 & 19.11 & 0.01 \\
\hline & Mild:Strong & 1 & 8.50 & 33.07 & 0.01 \\
\hline & Residuals & 8 & 2.06 & & \\
\hline \multirow[t]{4}{*}{ RLCS27 } & Mild & 1 & 0.06 & 0.99 & 0.51 \\
\hline & Strong & 1 & 0.05 & 0.77 & 0.45 \\
\hline & Mild:Strong & 1 & 3.43 & 55.08 & 0.00 \\
\hline & Residuals & 8 & 0.50 & & \\
\hline \multirow[t]{4}{*}{ RLCS13 } & Mild & 1 & 0.00 & 0.01 & 0.96 \\
\hline & Strong & 1 & 0.55 & 11.29 & 0.02 \\
\hline & Mild:Strong & 1 & 1.20 & 24.41 & 0.00 \\
\hline & Residuals & 8 & 0.39 & & \\
\hline \multirow[t]{4}{*}{ RLCS32 } & Mild & 1 & 4.35 & 26.68 & 0.00 \\
\hline & Strong & 1 & 7.73 & 47.34 & 0.00 \\
\hline & Mild:Strong & 1 & 23.84 & 146.09 & 0.00 \\
\hline & Residuals & 8 & 1.31 & & \\
\hline \multirow[t]{4}{*}{ RLCS18 } & Mild & 1 & 2.02 & 4.92 & 0.11 \\
\hline & Strong & 1 & 0.00 & 0.00 & 1.00 \\
\hline & Mild:Strong & 1 & 1.02 & 2.49 & 0.20 \\
\hline & Residuals & 8 & 3.29 & & \\
\hline \multirow[t]{4}{*}{ RLCS05 } & Mild & 1 & 1.26 & 25.75 & 0.00 \\
\hline & Strong & 1 & 0.30 & 6.06 & 0.05 \\
\hline & Mild:Strong & 1 & 15.64 & 320.18 & 0.00 \\
\hline & Residuals & 8 & 0.39 & & \\
\hline \multirow[t]{4}{*}{ RLCS08 } & Mild & 1 & 3.75 & 33.25 & 0.00 \\
\hline & Strong & 1 & 1.68 & 14.92 & 0.01 \\
\hline & Mild:Strong & 1 & 2.78 & 24.68 & 0.00 \\
\hline & Residuals & 8 & 0.90 & & \\
\hline \multirow[t]{4}{*}{ RLCS24 } & Mild & 1 & 0.10 & 5.25 & 0.11 \\
\hline & Strong & 1 & 0.20 & 10.26 & 0.02 \\
\hline & Mild:Strong & 1 & 0.20 & 10.59 & 0.02 \\
\hline & Residuals & 8 & 0.15 & & \\
\hline \multirow[t]{4}{*}{ RLCS23 } & Mild & 1 & 0.65 & 0.84 & 0.52 \\
\hline & Strong & 1 & 3.97 & 5.13 & 0.07 \\
\hline & Mild:Strong & 1 & 0.04 & 0.06 & 0.85 \\
\hline & Residuals & 8 & 6.18 & & \\
\hline \multirow[t]{4}{*}{ RLCS20 } & Mild & 1 & 0.09 & 1.84 & 0.38 \\
\hline & Strong & 1 & 0.05 & 1.02 & 0.39 \\
\hline & Mild:Strong & 1 & 0.29 & 6.31 & 0.06 \\
\hline & Residuals & 8 & 0.37 & & \\
\hline \multirow[t]{4}{*}{ RLCS25 } & Mild & 1 & 0.41 & 0.89 & 0.52 \\
\hline & Strong & 1 & 1.13 & 2.43 & 0.19 \\
\hline & Mild:Strong & 1 & 0.69 & 1.49 & 0.32 \\
\hline & Residuals & 8 & 3.70 & & \\
\hline \multirow[t]{2}{*}{ RLCS11 } & Mild & 1 & 6.85 & 55.56 & 0.00 \\
\hline & Strong & 1 & 8.29 & 67.20 & 0.00 \\
\hline
\end{tabular}

(Continued) 
TABLE 2 | Continued

\begin{tabular}{|c|c|c|c|c|c|}
\hline Isolate & Source & df & Sum Sq & $\boldsymbol{F}$ & $\begin{array}{c}p \text {-value } \\
\text { (Benjamini-Hochberg } \\
\text { corrected) }\end{array}$ \\
\hline & Mild:Strong & 1 & 3.75 & 30.43 & 0.00 \\
\hline & Residuals & 8 & 0.99 & & \\
\hline \multirow[t]{4}{*}{ RLCS03 } & Mild & 1 & 18.31 & 15.27 & 0.01 \\
\hline & Strong & 1 & 34.08 & 28.43 & 0.00 \\
\hline & Mild:Strong & 1 & 20.34 & 16.96 & 0.01 \\
\hline & Residuals & 8 & 9.59 & & \\
\hline \multirow[t]{4}{*}{ RLCSO4 } & Mild & 1 & 76.09 & 30.59 & 0.00 \\
\hline & Strong & 1 & 76.09 & 30.59 & 0.00 \\
\hline & Mild:Strong & 1 & 7.16 & 2.88 & 0.18 \\
\hline & Residuals & 8 & 19.90 & & \\
\hline \multirow[t]{4}{*}{ RLCSO2 } & Mild & 1 & 40.87 & 40.32 & 0.00 \\
\hline & Strong & 1 & 56.10 & 55.34 & 0.00 \\
\hline & Mild:Strong & 1 & 23.09 & 22.78 & 0.00 \\
\hline & Residuals & 8 & 8.11 & & \\
\hline \multirow[t]{4}{*}{ RLCS15 } & Mild & 1 & 11.36 & 13.86 & 0.02 \\
\hline & Strong & 1 & 23.69 & 28.90 & 0.00 \\
\hline & Mild:Strong & 1 & 5.09 & 6.21 & 0.06 \\
\hline & Residuals & 8 & 6.56 & & \\
\hline \multirow[t]{4}{*}{ RLCS01 } & Mild & 1 & 0.52 & 0.53 & 0.60 \\
\hline & Strong & 1 & 0.07 & 0.07 & 0.85 \\
\hline & Mild:Strong & 1 & 4.56 & 4.62 & 0.10 \\
\hline & Residuals & 8 & 7.90 & & \\
\hline \multirow[t]{4}{*}{ RLCS19 } & Mild & 1 & 0.00 & 0.02 & 0.96 \\
\hline & Strong & 1 & 2.30 & 9.93 & 0.02 \\
\hline & Mild:Strong & 1 & 0.01 & 0.03 & 0.87 \\
\hline & Residuals & 8 & 1.62 & & \\
\hline
\end{tabular}

The full results table is available in Supplementary Table S2. Bold indicates $p<0.05$.

In addition, our study can be viewed in the context of stress priming, for which criteria were previously established (AndradeLinares et al., 2016): (1) negative effect of strong perturbation (S); (2) significant interaction between mild and strong perturbations; and (3) the interaction term has a positive sign (MS $>S$ ).

We tested for phylogenetic signal for the measured trait categories using the phylosignal $\mathrm{R}$ package. We tested the null hypothesis of absence of signal (i.e., trait values are randomly distributed in the phylogeny) for five phylogenetic signal measures: The Moran's I index, the Abouheif's Cmean index, Blomberg's $\mathrm{K}$ and $\mathrm{K}^{*}$ and Pagel's $\mathrm{k}$.

\section{RESULTS}

Fungal isolates showed a range of responses to the applied sequences of temperature perturbation (Figures 2, 3). There was a significant interaction term for the two perturbations (M:S) in 16 tested isolates, and these were further categorized as antagonistic (13 isolates) or synergistic (3 isolates; Table 2). Isolates that did not meet the criterion of a significant interaction term (M:S) were assigned to the category 'additive' (16 isolates) (Tables 1, 2).

The observed antagonistic response is largely congruent (with small differences in categorization occurring, since two different statistical approaches are used - one isolate was classified differently) with what defines the priming ability of an organism (Andrade-Linares et al., 2016). We found priming responses in 12 out of the 32 isolates - 3 Mucoromycotina, 2 Basidiomycota, and 7 Ascomycota. That is, for these 12 isolates, growth was enhanced when fungi were exposed to a mild temperature pulse (M) before the severe temperature (MS), compared to when they were only experiencing the severe pulse $(\mathrm{S})$. For the remaining isolates exposure to experimental conditions of sequential perturbation (MS) did not lead to increased performance. Priming ability, antagonist response, additive response or synergistic response did not show a phylogenetic signal for any of the phylogenetic indices (Table 3).

\section{DISCUSSION}

Here we show that exposure of soil saprobic fungi isolates to the same sequence of pulse temperature perturbations results in a range of response types that include additive effect, antagony and synergy. The applied temperature pulse regime was exceeding the temperatures that are currently typically observed at the site from which isolates were obtained. The biggest proportion of isolates (16/32) responded in an additive manner to the perturbations. The synergistic response (two perturbations leading to decreased performance) was observed for $3 / 32$ isolates, meaning that such a sequence of perturbations could limit rates of processes (e.g., decomposition) these species carry out. On the other hand, the same temperature pulse regime resulted in an antagonistic response (two perturbations leading to an increased performance of an organism) for over $40 \%$ of isolates.

The observed antagonistic response of 12 isolates is congruent with priming ability of isolates. Priming ability of eight filamentous fungi isolates exposed to a rather different temperature sequence $\left(5 \mathrm{~h} / 35^{\circ} \mathrm{C}\right.$, then $\left.40^{\circ} \mathrm{C} / 10 \mathrm{~h}\right)$ has been shown previously (Andrade-Linares et al., 2016). The fact that a large proportion of our fungi showed this improved response to sequential stresses, even under different temperature regimes, may indicate that this priming ability is not an exceptional response, but rather a well-established phenomenon that can help fungi deal with adverse effects.

TABLE 3 | Phylogenetic signal test for priming ability (PRI), antagonist response (ANT), additive response (ADD), and synergistic response (SYN).

\begin{tabular}{lccccc}
\hline & Cmean & I & K & K.star & Lambda \\
\hline Statistics & & & & & \\
PRI & 0.0439 & -0.0906 & 0.0420 & 0.0478 & $5.385 \mathrm{e}-05$ \\
ANT & 0.1105 & -0.0604 & 0.0458 & 0.0514 & $6.37 \mathrm{e}-05$ \\
ADD & 0.1413 & -0.0404 & 0.0522 & 0.0573 & $7.97 \mathrm{e}-05$ \\
SYN & -0.0959 & -0.0481 & 0.1514 & 0.1733 & $7.97 \mathrm{e}-05$ \\
$\boldsymbol{P}$-values & & & & & \\
PRI & 0.274 & 0.783 & 0.901 & 0.883 & 1 \\
ANT & 0.129 & 0.603 & 0.726 & 0.716 & 1 \\
ADD & 0.082 & 0.538 & 0.521 & 0.513 & 1 \\
SYN & 0.665 & 0.679 & 0.715 & 0.723 & 1
\end{tabular}


In addition, the observed exacerbation of growth inhibition of three treated isolates (RLCS06, RLCS12, and RLCS24) due to sequential heat exposure has not been observed before. For these fungi, the first heat stress event clearly did not help them in dealing with the second, more severe heat pulse. These would therefore be interesting targets to study further in the context of climate change and heat extremes.

At the species level, physiological stress regimes are known to set biogeographic limits and determine microhabitat preferences. Organismal responses to extreme heat events include redirecting resources from growth to survival that may include transition to a dormancy state or sporulation. These variations in heat responses are species specific and may be caused by differences in cellular HSP (heat shock proteins) production, altered membrane composition and carbohydrate flux (Morano et al., 2012; Bérard et al., 2015). The difference in response to sequential temperature pulse perturbation in isolates originating from one fungal assembly may indicate differences in sensitivity and diverse stress tolerances.

Our results show that recurrent environmental perturbations such as extreme temperature events influence a group of soil filamentous fungi originating from the same site in various ways. Thus, the patterns of responses that they exhibit to the sequence of thermal pulses might be one of the factors that contribute to shaping soil fungal community composition. Such differences in aspects of the 'thermal niche' may contribute to coexistence of fungi in the community, much like differences among species in other abiotic factors or resource utilization patterns.

\section{CONCLUSION}

We focused on growth responses of multiple isolates of soil filamentous fungi, originating from the same grassland to a sequence of thermal pulses. These fungal isolates, isolated from the same soil, revealed the full range of possible responses to an identical heat perturbation sequence. This diversity of responses could have consequences for soil-borne ecosystem processes, highlighting the potential importance of fungal biodiversity in maintaining such services, particularly in the context of climate change.

\section{REFERENCES}

Alley, R. B., Marotzke, J., Nordhaus, W. D., Overpeck, J. T., Peteet, D. M., Pielke, R. A., et al. (2003). Abrupt climate change. Science 299, 2005-2010. doi: 10.1126/ science. 1081056

Allison, S. D., and Martiny, J. B. H. (2008). Resistance, resilience, and redundancy in microbial communities. Proc. Natl. Acad. Sci. U.S.A. 105(Suppl. 1), 1151211519. doi: 10.1073/pnas.0801925105

Andrade-Linares, D. R., Veresoglou, S. D., and Rillig, M. C. (2016). Temperature priming and memory in soil filamentous fungi. Fungal Ecol. 21, 10-15. doi: 10.1016/j.funeco.2016.02.002

Bahn, M., Reichstein, M., Dukes, J. S., Smith, M. D., and Mcdowell, N. G. (2014). Climate-biosphere interactions in a more extreme world. New Phytol. 202, 356-359. doi: 10.1111/nph.12662

Bárcenas-Moreno, G., Brandón, M. G., Rousk, J., and Bååth, E. (2009). Adaptation of soil microbial communities to temperature: comparison of fungi and bacteria

\section{AUTHOR'S NOTE}

An earlier version of this manuscript has been released as a Pre-Print at bioRxiv (Szymczak et al., 2019).

\section{DATA AVAILABILITY STATEMENT}

The raw data supporting the conclusions of this article will be made available by the authors, without undue reservation, to any qualified researcher.

\section{AUTHOR CONTRIBUTIONS}

AS and MCR designed the research and wrote the manuscript. AS performed the research. AS, JR, and MR performed the data analyses. All authors contributed to the final version of the manuscript.

\section{FUNDING}

We acknowledge funding for CRC 973 'Priming and memory of organismic responses to stress' from the German Research Foundation (DFG; project number 190578797). We acknowledge support by the Open Access Publication Initiative of Freie Universität Berlin.

\section{ACKNOWLEDGMENTS}

We thank Mehmet Akif Celiker for help with experimental work.

\section{SUPPLEMENTARY MATERIAL}

The Supplementary Material for this article can be found online at: https://www.frontiersin.org/articles/10.3389/fmicb. 2020.01326/full\#supplementary-material

in a laboratory experiment. Glob. Change Biol. 15, 2950-2957. doi: 10.1111/j. 1365-2486.2009.01882.x

Bérard, A., Ben Sassi, M., Kaisermann, A., and Renault, P. (2015). Soil microbial community responses to heat wave components: drought and high temperature. Clim. Res. 66, 243-264. doi: 10.3354/cr01343

Côté, I. M., Darling, E. S., and Brown, C. J. (2016). Interactions among ecosystem stressors and their importance in conservation. Proc. R. Soc. B Biol. Sci. 283:20152592. doi: 10.1098/rspb.2015.2592

Crain, C. A., Kroeker, K., and Halpern, B. S. (2008). Interactive and cumulative effects of multiple human stressors in marine systems. Ecol. Lett. 11, 1304-1315. doi: 10.1111/j.1461-0248.2008.01253

Crowther, T. W., and Bradford, M. A. (2013). Thermal acclimation in widespread heterotrophic soil microbes. Ecol. Lett. 16, 469-477. doi: 10.1111/ele.12069

Fischer, E. M., and Knutti, R. (2015). Anthropogenic contribution to global occurrence of heavy-precipitation and high-temperature extremes. Nat. Clim. Change 5, 560-564. doi: 10.1038/nclimate2617 
Foster, C. N., Sato, C. F., Lindenmayer, D. B., and Barton, P. S. (2016). Integrating theory into disturbance interaction experiments to better inform ecosystem management. Glob. Change Biol. 22, 1325-1335. doi: 10.1111/gcb. 13155

Frank, D., Reichstein, M., Bahn, M., Thonicke, K., Frank, D., Mahecha, M. D., et al. (2015). Effects of climate extremes on the terrestrial carbon cycle: concepts, processes and potential future impacts. Glob. Change Biol. 21, 2861-2880. doi: $10.1111 /$ gcb. 12916

Hanson, C. E., Palutikof, J. P., Dlugolecki, A., and Giannakopoulos, C. (2006). Bridging the gap between science and the stakeholder: the case of climate change research. Clim. Res. 31, 121-133. doi: 10.3354/cr031121

Hilker, M., Schwachtje, J., Baier, M., Balazadeh, S., Bäurle, I., Geiselhardt, S., et al. (2016). Priming and memory of stress responses in organisms lacking a nervous system. Biol. Rev. 49, 1118-1133. doi: 10.1111/brv.12215

Hortal, S., Powell, J. R., Plett, J. M., Simonin, A., and Anderson, I. C. (2016). Intraspecific competition between ectomycorrhizal Pisolithus microcarpus isolates impacts plant and fungal performance under elevated $\mathrm{CO}_{2}$ and temperature. FEMS Microbiol. Ecol. 92:fiw113. doi: 10.1093/femsec/ fiw 113

IPCC (2018). Global Warming of $1.5^{\circ} \mathrm{C}$. An IPCC Special Report on the Impacts of Global Warming of $1.5^{\circ} \mathrm{C}$ Above Pre-Industrial Levels and Related Global Greenhouse Gas Emission Pathways, in the Context of Strengthening the Global Response to the Threat of Climate Change, Sustainable Development, and Efforts to Eradicate Poverty, eds V. Masson-Delmotte, P. Zhai, H. O. Pörtner, D. Roberts, J. Skea, P. R. Shukla, et al. (Geneva: IPCC).

Jentsch, A., Kreyling, J., and Beierkuhnlein, C. (2007). A new generation of events, not trends experiments. Front. Ecol. Environ. 5, 365-374. doi: 10.1890/1540929520075[365:ANGOCE]2.0.CO;2

Kayler, Z. E., De Boeck, H. J., Fatichi, S., Grünzweig, J. M., Merbold, L., Beier, C., et al. (2015). Experiments to confront the environmental extremes of climate change. Front. Ecol. Environ. 13, 219-225. doi: 10.1890/140174

Kreyling, J., and Beier, C. (2013). Complexity in climate change manipulation experiments. Bioscience 63, 763-767. doi: 10.1525/bio.2013.63.9.12

Lehmann, A., Zheng, W., Soutschek, K., Roy, J., Yurkov, A., and Rillig, M. C. (2019). Tradeoffs in hyphal traits determine mycelium architecture in saprobic fungi. Sci. Rep. 9:14152. doi: 10.1038/s41598-019-50565-7

Lloret, F., Escudero, A., Iriondo, J. M., Martinez-Vilalta, J., and Valladarez, F. (2012). Extreme climatic events and vegetation: the role of stabilizing processes. Glob. Change Biol. 18, 797-805. doi: 10.1111/j.1365-2486.2011.02624.x

Mittler, R. (2006). Abiotic stress, the field environment and stress combination. Trends Plant Sci. 11, 15-19. doi: 10.1016/j.tplants.2005.11.002
Morano, K. A., Grant, C. M., and Moye-Rowley, W. S. (2012). The response to heat shock and oxidative stress in saccharomyces cerevisiae. Genetics 190, 1157-1195. doi: 10.1534/genetics.111.128033

Norris, T. B., Wraith, J. M., Castenholz, R. W., and McDermott, T. R. (2002). Soil microbial community structure across a thermal gradient following a geothermal heating event. Appl. Environ. Microbiol. 68, 6300-6309. doi: 10. 1128/AEM.68.12.6300-6309.2002

Piggott, J. J., Townsend, C. R., and Matthaei, C. D. (2015). Reconceptualizing synergism and antagonism among multiple stressors. Ecol. Evol. 5, 1538-1547. doi: 10.1002/ece3.1465

Rillig, M. C., Rolff, J., Tietjen, B., Wehner, J., and Andrade-Linares, D. R. (2015). Community priming-effects of sequential stressors on microbial assemblages. FEMS Microbiol. Ecol. 91:fiv040. doi: 10.1093/femsec/fiv040

Rillig, M. C., Ryo, M., Lehmann, A., Aguilar-Trigueros, C. A., Buchert, S., Wulf, A., et al. (2019). The role of multiple global change factors in driving soil functions and microbial biodiversity. Science 366, 886-890. doi: 10.1126/science.aay2832

Ryo, M., Aguilar-Trigueros, C. A., Pinek, L., Muller, L. A. H., and Rillig, M. C. (2019). Basic principles of temporal dynamics. Trends Ecol. Evol. 34, 723-733. doi: 10.1016/j.tree.2019.03.007

Szymczak, A., Ryo, M., and Rillig, M. C. (2019). Diversity of responses of soil saprobic fungi to recurring heat events. BioRxiv [Preprint]. doi: 10.1101/733923

Thompson, R. M., Beardall, J., Beringer, J., Grace, M., and Sardina, P. (2013). Means and extremes: building variability into community-level climate change experiments. Ecol. Lett. 16, 799-806. doi: 10.1111/ele.12095

Vázquez, D. P., Gianoli, E., Morris, W. F., and Bozinovic, F. (2015). Ecological and evolutionary impacts of changing climatic variability. Biol. Rev. 92, 22-43. doi: 10.1111/brv.12216

Zhou, W. P., Shen, W. J., Li, Y. E., and Hui, D. F. (2017). Interactive effects of temperature and moisture on composition of the soil microbial community. Eur. J. Soil Sci. 68, 909-918. doi: 10.1111/ejss.12488

Conflict of Interest: The authors declare that the research was conducted in the absence of any commercial or financial relationships that could be construed as a potential conflict of interest.

Copyright (C) 2020 Szymczak, Ryo, Roy and Rillig. This is an open-access article distributed under the terms of the Creative Commons Attribution License (CC BY). The use, distribution or reproduction in other forums is permitted, provided the original author(s) and the copyright owner(s) are credited and that the original publication in this journal is cited, in accordance with accepted academic practice. No use, distribution or reproduction is permitted which does not comply with these terms. 